\title{
Percepciones de estudiantes sobre los programas de orientación en la provincia de Concepción, Chile
}

Students perception about orientation programs in Concepción province, Chile

\section{Volumen 20, Número 2 \\ Mayo - Agosto \\ pp. 1-27}

\author{
Angélica Corrales Huenul \\ Eduardo Arriagada Valenzuela \\ Sergio Soto Peranchiguay
}

Citar este documento según modelo APA

Corrales Huenul, Angélica., Arriagada Valenzuela, Eduardo y Soto Peranchiguay, Sergio. (2020). Percepciones de estudiantes sobre los programas de orientación en la provincia de Concepción, Chile. Revista Actualidades Investigativas en Educación, 20(2), 1-27. Doi. 10.15517/aie.v20i2.41652 


\title{
Percepciones de estudiantes sobre los programas de orientación en la provincia de Concepción, Chile \\ Students perception about orientation programs in Concepción province, Chile
}

\author{
Angélica Corrales Huenul ${ }^{1}$ \\ Eduardo Arriagada Valenzuela² \\ Sergio Soto Peranchiguay ${ }^{3}$
}

\begin{abstract}
Resumen: Los cambios que debe enfrentar el sistema escolar en coherencia con los desafíos de la sociedad contemporánea hacen necesario que el profesorado reflexione en forma crítica sobre las prácticas pedagógicas. El presente artículo expone los resultados de un estudio realizado acerca del desarrollo de los programas de Orientación en la provincia de Concepción - Chile desde la percepción estudiantil que realiza su práctica pedagógica en centros educativos. El objetivo general de esta investigación fue conocer cómo estudiantes de pedagogía perciben el desarrollo e implementación de los planes y programas de orientación en los centros de práctica profesional, durante el último año de formación académica. La investigación se enmarca en un enfoque cuantitativo y consiste en un estudio descriptivo que analiza cuatro dimensiones. Para la recolección de datos se utilizó una encuesta tipo Likert, la que incluyó una pregunta abierta. El instrumento se aplicó a estudiantes de 12 carreras de pedagogía, distribuidos en 98 centros de práctica profesional, durante el año 2017. Los resultados obtenidos demuestran que las dimensiones mejor evaluadas fueron el conocimiento y las estrategias metodológicas. Sin embargo, existe una percepción negativa en relación con las dimensiones de asesoría, capacitación y efectividad de los programas de orientación en el aula.
\end{abstract}

Palabras clave: programas de educación, estudiantes universitarios, orientación pedagógica.

Abstract: The changes that the school system must face in coherence with the challenges of contemporary society make it necessary for teachers to reflect critically on pedagogical practices. This article presents the results of a study carried out on the development of Orientation programs in the province of Concepción - Chile from the perception of the students who carry out their pedagogical practice in educational centers. The general objective of this research is to know how pedagogy students perceive the development and implementation of orientation plans and programs in professional practice centers during the last year of academic training. The research is framed in a quantitative approach and consists of a descriptive study that analyzes four dimensions. For data collection, a Likert-type survey was used, which included an open-ended question. The instrument was applied to students of 12 careers of pedagogy, distributed in 98 professional practice centers, during the year 2017. The results obtained show that the best evaluated dimensions were knowledge and methodological strategies. However, there is a negative perception regarding the dimensions of counseling, training, and effectiveness of classroom orientation programs

Key words: education programs, university students, pedagogical orientation

\footnotetext{
${ }^{1}$ Docente de la Universidad de Concepción, Chile, del departamento de Ciencias de la Educación, Facultad de Educación.Dirección electrónica: acorrales@udec.cl Orcid https://orcid.org/0000-0002-2593-2053

${ }^{2}$ Docente Liceo Bicentenario Valentín Letelier Madariaga, Chile. Dirección electrónica: earriagadav@udec.cl Orcid https://orcid.org/0000-0002-1453-0489

${ }^{3}$ Docente Liceo Bicentenario de excelencia y alta exigencia San José U.R, Chile. Dirección electrónica: sergiosoto@udec.cl Orcid https://orcid.org/0000-0001-6891$\underline{0092}$
}

Artículo recibido: 24 de octubre, 2019

Enviado a corrección: 20 de febrero, 2020

Aprobado: 23 de abril, 2020 


\section{Introducción}

En el presente estudio nos planteamos la siguiente interrogante ¿Cómo percibe el estudiantado de pedagogía de la Universidad de Concepción de Chile el desarrollo de los programas de orientación en los centros educativos? Esta investigación reviste una vital importancia debido al rol que debe cumplir la orientación educativa en los centros formativos. La misión de los programas de orientación es encausar de manera correcta y eficiente los distintos aspectos que relacionan al alumnado con su desarrollo académico, personal, social y profesional. Los centros educativos deben estar en una constante evolución y actualización, con el objeto de atender eficientemente las distintas necesidades que la sociedad presenta. En tal sentido, un desarrollo óptimo de los programas de orientación permitirá que los centros educativos logren metas académicas, desarrollen sus potencialidades en sus respectivas áreas de interés y fomenten la autonomía y la toma de decisiones de manera consciente. Por lo anterior, resulta fundamental conocer cómo se implementan y desarrollan los programas de orientación en nuestro país y cuál es la percepción al respecto de las personas encargadas de ejecutarlos en el aula.

En Chile, la asignatura de Orientación tiene su origen en la promulgación del decreto $N^{\circ} 4.002$ del 20 de mayo de 1980. En tal documento se establecieron los Objetivos, Planes y Programas de la educación general básica, que debía implementar el Ministerio de Educación de Chile (en adelante MINEDUC), a partir del año 1981 (2017, p. 9). Tal decreto permitió que se generaran instancias para el desarrollo de la orientación dentro de los horarios escolares. Posteriormente, el decreto N³00 del 22 de enero de 1982 le otorgó una definición más formativa al consejo de curso, definiéndolo con una orientación de carácter colectivo e incorpora diversos objetivos a cumplir. En el año 1990, con la promulgación de la Ley Orgánica Constitucional (en adelante LOCE) (Ley №18692, 1990), se dotó de una base al área formativa del consejo de curso y se creó la orientación como un subsector educativo. Los lineamientos y directrices se entregaron a través de la Circular N600 en el año 1991, la que promovía el desarrollo adecuado de la orientación en el sistema escolar.

Otro antecedente significativo es la Ley General de Educación, (en adelante LGE), donde los Objetivos Fundamentales y los Contenidos Mínimos Obligatorios son reemplazados por las Bases Curriculares. Tales bases presentan los Objetivos de Aprendizaje por nivel para cada asignatura; y los Objetivos Fundamentales Transversales, que establecen las metas generales de la educación escolar. En el año 2014 se promulgan las Bases Curriculares específicas para el área de Orientación, correspondientes a los 
niveles de séptimo y octavo en enseñanza básica, y primero y segundo en enseñanza media. Si bien, el Mineduc autorizó su implementación a partir del año 2015, los programas de estudio aparecieron en el año 2016. Estos últimos consisten en una sugerencia del Mineduc de cómo llevar a cabo los objetivos que se presentan en las bases curriculares (Mineduc, 2015 p. 340).

De manera general, la orientación educativa es un proceso asiduo a lo largo de todo el periodo escolar y está a cargo de diversos agentes (Sanz, 2010, p. 349). Álvarez y Bisquerra la consideran una vía para personalizar la educación y, de esta forma, promover valores y el desarrollo de habilidades y competencias para la vida, ya que se trata de un proceso de ayuda y asesoramiento continuo del alumnado en todos sus aspectos (como se cita en García, 2016, p.16). Domingo, Fernández y Barrero señalan que la orientación educativa, tras un largo recorrido, ha logrado tener un lugar, un prestigio y un importante espacio en el profesionalismo. Además, durante los últimos años, se observa un importante cambio en la forma de comprender el desarrollo de la orientación educativa por parte de los profesionales de la especialidad (como se cita en García, 2016, p. 16).

En este escenario, se considera necesario conocer la percepción acerca del desarrollo de los programas de orientación en los centros educativos. Por ello, en la Universidad de Concepción de Chile, durante el primer semestre académico del año 2017 y por un período de 5 meses, se lleva a cabo una investigación que tiene por objetivo general conocer la percepción sobre el desarrollo de los programas de orientación en los centros educativos, del estudiantado en práctica profesional de todas las carreras de pedagogía en educación secundaria en la provincia de Concepción. De este objetivo general se desprenden los siguientes objetivos específicos: 1. Identificar y analizar el nivel de apoyo que recibe el estudiantado en práctica profesional con jefatura de curso de parte del establecimiento educacional para el desarrollo de los programas de orientación. 2. Conocer si el estudiantado en práctica pedagógica considera que los programas de orientación son coherentes con el contexto de los respectivos centros educativos donde se ejecutan. 3. Determinar la percepción que tiene el estudiantado en práctica profesional respecto a las estrategias metodológicas del centro educativo para la ejecución de los programas de orientación. 4. Describir y analizar la percepción del estudiantado en práctica pedagógica acerca de la efectividad de los programas de orientación y el efecto en el estudiantado del centro respectivo. 
Para recoger la información necesaria se diseñó un cuestionario tipo Likert ${ }^{2}$. instrumento involucra distintas dimensiones acerca de la ejecución de los programas en los centros educativos y la relación entre et alumnado en práctica profesional, los centros educativos y los receptores de los programas de orientación. Entre las dimensiones están: a) asesoría y capacitación, b) conocimiento, c) estrategias metodológicas y d) efectividad de los programas de orientación en el aula. El estudio se aborda desde una perspectiva cualitativa, la cual busca, a través de un análisis de respuestas, identificar falencias o fortalezas que el estudiantado de pedagogía logró evidenciar durante su proceso de práctica profesional. Los resultados se muestran en el desarrollo del documento.

\section{Referente teórico}

\subsection{Antecedentes históricos de la Orientación en América latina.}

La orientación, como eje de desarrollo profesional, es una actividad de reciente adaptación en América Latina, a diferencia de lo que sucede en otras partes del mundo como Estados Unidos o Europa. La actividad de orientación se ha caracterizado por una frecuente evolución en concordancia con las distintas situaciones de transformación social, políticas y económicas a nivel latinoamericano (González y Ledezma, 2009, p. 1). En el último tiempo, se observa un progresivo aumento de profesionales de la orientación, quienes detentan funciones relevantes en centros gubernamentales, como en los ministerios de educación y establecimientos educacionales; así como también en el sector privado.

Si bien, los intereses de los países latinoamericanos son diversos, necesitan unificar criterios para avanzar de manera unificada en el ámbito de la Orientación. Ello debido a las diversas problemáticas en esta área como campo de desarrollo profesional, que son comunes en los países latinoamericanos. Dentro de tales dificultades, Melo-Silva destaca la ineficiencia o la no existencia de políticas públicas, que permitan implementar los conocimientos de este campo profesional en la sociedad, además de la falta de claridad para definir la labor del orientador (como se cita en González, 2008, p. 46).

Es justo mencionar que muchos países latinoamericanos han realizado grandes esfuerzos con el objeto de mejorar la orientación como actividad profesional. Sin embargo, diversos autores sostienen que es necesario repensar y redefinir todo lo relacionado con la teoría y práctica de este campo profesional. En este sentido, Olivera señala que los cambios

\footnotetext{
${ }^{2}$ Ver en anexos. Instrumento creado para los efectos de esta investigación (2017).
} 
no solo deben ser técnicos, sino también direccionados a formar personas con conciencia (como se cita en González y Ledezma, 2009, p. 9).

\subsection{La Orientación en el centro educativo}

\subsubsection{Conceptualización del proceso de Orientación}

Resulta complejo conceptualizar el término orientación. La teoría no llega a un consenso sobre los objetivos, el campo de acción y las diversas dimensiones (educativa, personal, vocacional, escolar, profesional, etc.) que abarca el concepto. A lo anterior se suma la plurisignificación del término, que puede ser entendido como la forma en la que intervienen los orientadores y orientadoras; así como también, la disparidad de funciones asignadas a estos profesionales (diagnóstico, asesoramiento, terapia, consejo, enseñanza, etc.) (Parras et al. 2008, p. 33).

Coloquialmente, la palabra orientación se relaciona con guiar, aconsejar, sugerir, encaminar, encausar, entre otras. Desde el punto de vista académico, nos encontramos con distintas acepciones. Al respecto, Johnston define el proceso de orientación como "ayuda que se presta a las personas para que resuelvan sus problemas y tomen decisiones prudentes" (como se cita en Molina, 2004, p. 2). Parras et al. señalan que la orientación corresponde a "una intervención individual y directa (según el modelo de consejo) orientada a la resolución de los problemas del sujeto" (Parras et al., 2008, p. 33). De acuerdo con Boza, la orientación es concebida como "proceso de ayuda continuo y sistemático, dirigido a todas las personas y en todos sus aspectos, poniendo énfasis especial en la prevención y el desarrollo que se realiza a lo largo de toda la vida" (como se cita en Parras, et al, 2008, p. 34). Mientras que, Rodríguez sostiene que la orientación es un proceso que tiene por objetivo guiar, conducir o acompañar a los individuos en los procesos de autoconocimiento (como se cita en Tarrida, 2012, p. 25).

Las diversas definiciones mencionadas difieren en cuanto a la amplitud de elementos que consideran para su formulación. Sin embargo, existe un factor común en todas ellas, la idea de apoyar al individuo. Si además consideramos los factores transversales que involucran al individuo con el entorno y contexto, podemos proponer una conceptualización del término. Podemos definirla como un proceso de asesoramiento continuo de profesionales a determinados sujetos, con el objeto de que estos últimos actúen de manera independiente y consiente, y sean capaces de desenvolverse satisfactoriamente en los distintos aspectos que les imponga la sociedad, en los contextos en los que se desenvuelven. 


\subsubsection{La orientación educativa en el centro escolar}

Actualmente, la orientación educativa en Chile ha adquirido relevancia gracias a la implementación de diversas políticas públicas. De esta manera, el estudiantado de los centros educativos recibe una formación cada vez más sólida en aspectos que involucran diferentes áreas de desarrollo.

Como se ha postulado en este artículo, resulta complejo definir el concepto de orientación y su rol en los centros educativos. Sin embargo, podemos obtener una concepción más precisa si le damos un enfoque particular en el ámbito educativo. GarcíaLoor y Chancay (2016, p. 112) señalan que:

El término Orientación Educativa es un proceso continuo y sistemático, que debe darse a lo largo de la vida del individuo, su finalidad es contribuir a la formación integral de su personalidad para que se constituya en actor de su propio desarrollo.

Secaira señala que la orientación educativa se fundamenta en la educación integral, en la que existe una preocupación constante acerca del destino estudiantil, comprendiendo las tendencias, vocación y capacidades de los y las estudiantes (citado en García-Loor y Chancay, 2016, p. 112).

Nereci (1990) sostiene que "la orientación educativa es un proceso mediante el cual se asiste al educando con el fin de que este pueda tener pleno rendimiento de sus actividades escolares, y alcanzar de manera armónica los fines de la educación integral" (como se cita en Molina, 2004, p. 5).

Ayala señala que:

La Orientación Educativa es un proceso que involucra asesoramiento continuo en el cual el profesor promueve distintos tipos de actividades de carácter preventivo y dirigidos principalmente a la formación de hábitos de estudio, a la concentración y atención en clases, el aprovechamiento eficiente del tiempo y el desarrollo de habilidades cognitivas. (como se cita en Molina, 2004, p. 5)

De acuerdo con Vélaz de Medrano, la orientación educativa es un conjunto de metodologías, conocimientos y principios técnicos que se dirigen hacia las personas con el fin de facilitar y promover el desarrollo integral del sujeto. (como se cita en Parras, et al, 2008, pp. 33-34). 
Las personas autoras que se citan definen la orientación educativa desde distintas perspectivas, sin embargo, coinciden en los fundamentos, las funciones y los objetivos. En efecto, indican que la orientación es un proceso de intervención sistemática que busca ayudar al alumnado y a sus pares. Agregan que el profesorado no es el único responsable del proceso en un establecimiento, sino que intervienen todos los agentes responsables de la formación educacional. De esta manera, cada participante cumple una función particular y contribuye a la consecución de un objetivo común.

En suma, la orientación educativa es un proceso fundamental para encausar correctamente al alumnado. La implementación de la orientación educativa logra que el estudiantado se desenvuelva íntegramente en la sociedad y alcancen un desarrollo pleno de habilidades. Para ello, se requiere que el profesorado reflexione sobre los diversos procesos de aprendizaje en todos sus aspectos (Pérez y Osses, 2015, p. 221). Asimismo, se requiere de un desempeño responsable y competencias profesionales fundamentales en su ejecución.

\subsection{Agentes del proceso de Orientación Educativa}

La implementación y desarrollo de la orientación en un centro educativo involucra a distintos participantes. En efecto, en el proceso intervienen diversos agentes vinculados a la educación y cada uno de ellos cumple una función determinada. Se extiende esta responsabilidad a todos los y las participantes de la comunidad escolar, incluida la familia, la que se considera un pilar fundamental en el logro de los objetivos.

Álvarez (como se cita en Parras et al., 2008, p. 212) señala que los principales agentes de la orientación educativa son:

- El equipo de docentes, quienes deben promover un buen ambiente de aprendizaje. En otras palabras, deben garantizar una buena relación y una comunicación efectiva entre et alumnado y las personas encargadas de la acción tutorial. Además, deben promover oportunidades de desarrollo para el estudiantado, a través de diversas herramientas. De esta manera, los y las docentes manifiestan el compromiso educativo hacia sus alumnos. (Jiménez, 2008, p. 329-330)

- La orientadora u orientador del centro educativo. El o la profesional especializada debe supervisar, asesorar y colaborar con el trabajo que realiza la persona encargada de la acción tutorial. De acuerdo con Garrido, Krichesky y Barrera (2010, p. 111), el orientador $\mathrm{u}$ orientadora educacional debe guiar la labor docente, teniendo siempre 
como objetivo la mejora de cada estudiante. Asimismo, el orientador u orientadora debe entregar el material, las estrategias y metodologías necesarias para cumplir de la mejor manera los objetivos generales y/o particulares que se persigan.

- El alumnado del centro educativo es otro agente importante para que el proceso se lleve a cabo. Esta población debe tener un rol activo en las distintas actividades 0 procedimientos que se realicen en relación con la orientación educativa que reciben.

- Los padres y las madres o quien sean responsable de la educación del estudiantado. Según señala González-Pienda (2007, p. 197), las condiciones familiares afectan significativamente el desarrollo de los procesos cognitivos y motivacionales del alumnado, lo cual influye en cómo este enfrenta su proceso educacional.

- El equipo multidisciplinario de orientación, que asesora, coordina e impulsa el proceso de orientación dentro de un centro educativo y debe cubrir eficientemente las distintas áreas, en las que el estudiantado necesite asesoramiento.

- Agente encargado de la acción tutorial del curso. Este debe coordinar la acción tutorial del estudiantado y todas aquellas actividades que involucren el desarrollo personal y académico dentro y fuera del aula. Según señalan Albornoz y Costa la actividad tutorial, en el contexto de la educación, se refiere a una vigilancia estrecha y a una orientación sistemática de los grupos de estudiantes (como se cita en De Abreu, De Abreu y Albornoz, 2014, pp. 10-11), Deben estar a cargo de ello, personas con experiencia en el campo de la formación. Asimismo, es importante mencionar que el modo de transmitir la acción tutorial, la forma de evaluar y el tipo de relación entre el profesorado y el alumnado a cargo, tiene influencia en las diversas experiencias que pueda enfrentar eventualmente una persona.

\subsection{Práctica pedagógica}

La práctica pedagógica admite diversas definiciones. Díaz la define como el conjunto de actividades cotidianas que realizamos en el aula o en espacios educativos alternativos. Dentro de los componentes de la práctica pedagógica, tenemos a docentes, el currículo, et alumnado y el proceso formativo (como se cita en Díaz, 2006, p. 90). Huberman la conceptualiza como un proceso consciente y deliberado, que es implementado por un sistema educativo, con el fin de mejorar el desempeño del estudiantado. Para tales efectos se estimula el desarrollo estudiantil en los diversos campos en los que puedan desenvolverse según sus intereses (como se cita en Moreno, 2002, p. 7). 
Independientemente de la definición que acuñemos, es importante destacar el rol docente. La labor del profesorado en el aula no se limita a transmitir conocimiento teórico, sino que debe entregar, entre otras cosas, orientación y las herramientas necesarias para que el estudiantado aproveche al máximo las oportunidades que le brinda el sistema. El profesorado contribuye a la formación del estudiantado en las diversas áreas de aprendizaje. Ello implica que cada docente, como persona encargada del proceso de orientación estudiantil, debe desarrollar habilidades para superar sus propias limitaciones y conflictos; de esta manera, logrará ser un aporte genuino a la formación orientadora.

\subsection{Bases curriculares y programas de Orientación en Chile}

Las Bases Curriculares derivan de la Ley General de Educación (LGE) y, de acuerdo con el Mineduc (2017) se deben aplicar en todo el país. Las bases definen los Contenidos Mínimos Obligatorios (CMO) y los Objetivos Generales para cada nivel respectivamente.

La enseñanza en Chile se estructura en educación básica y media. La educación básica, mediante Decreto Exento de Educación № 584/07, comprende tres niveles: el primer nivel comprende primero a cuarto básico; segundo nivel, quinto y sexto; tercer nivel, séptimo y octavo. La educación media, a través del Decreto Exento de Educación № 1000/09, comprende primero, segundo, tercero y cuarto medio. En Chile, las bases curriculares están definidas solamente para para los niveles de séptimo y octavo, en enseñanza básica, y primero y segundo en enseñanza media.

Las bases curriculares, de acuerdo (Mineduc, 2015, pp. 345-347) con el trabajan en torno a cinco ejes comunes en todos los niveles. Cada eje aumenta en profundización y complejidad de manera progresiva a medida en que se avanza de un nivel a otro (lapso de un año). Los ejes de trabajo son los siguientes:

- Crecimiento Personal. Se trabaja el conocimiento de la persona, su historia, desarrollo, afectividad y sexualidad.

- Bienestar y Autocuidado. Se trabajan los estilos de vida saludable y la prevención del consumo de sustancias.

- Relaciones Interpersonales. Se tratan las relaciones con las demás personas y la resolución de conflictos.

- Pertenencia y Participación Democrática. Los temas son la pertenencia a un grupo de personas, la responsabilidad y la organización. 
- Gestión y Proyección del Aprendizaje. Se trabajan los hábitos de estudio, la metacognición y la autonomía.

El Mineduc propone los programas de orientación. Estos comprenden actividades organizadas y rígidas, así como también orientaciones y sugerencias para implementar, planificar y evaluar el desarrollo de los ejes temáticos según el contexto y el nivel educacional. Los establecimientos educacionales tienen la libertad de adoptar los objetivos y programas propuestos, de acuerdo con necesidades educativas e intereses del estudiantado respectivamente.

\section{Metodología}

\subsection{Enfoque}

El objetivo de la presente investigación es conocer la percepción del estudiantado en práctica profesional en educación secundaria de la Facultad de Educación de la Universidad de Concepción, sobre la implementación y desarrollo de los programas de orientación en los establecimientos educacionales. El estudio se llevó a cabo durante el primer semestre académico del año 2017. Se consideró pertinente abordarlo desde una perspectiva cuantitativa, con un alcance descriptivo y exploratorio. Lo anterior, de acuerdo con Hernández, Fernández y Baptista (2006), quienes consideran que en este tipo de investigaciones se miden diversos aspectos, componentes o dimensiones del fenómeno a investigar para su posterior interpretación.

En la investigación se pretende conocer la percepción de las personas encuestadas respecto al desarrollo de los programas de orientación a nivel de 4 dimensiones. Estas son: conocimiento para abordar las temáticas que indican los programas de orientación, asesoría aportada por sus docentes guías, desarrollo de estrategias metodológicas y efectividad percibida por la población encuestada en relación con el abordaje de los programas en los centros educativos. Además, se incorporó una pregunta abierta que busca identificar las falencias y fortalezas de la población encuestada durante el periodo de su práctica pedagógica.

\subsection{Población de estudio}

La población para este estudio consistió en la totalidad del estudiantado de pedagogía en educación secundaria de las distintas especialidades de la Facultad de educación de la 
Universidad de Concepción. El criterio utilizado para la selección de las personas participantes fue intencional, a conveniencia del estudio; y corresponden a todo el estudiantado de la facultad antes mencionada, que realizaba su práctica profesional, correspondiente a las carreras de: Pedagogía en Matemáticas, Pedagogía en Historia, Pedagogía en Español, Pedagogía en Física, Pedagogía en Química, Pedagogía en Biología, Pedagogía en Inglés, Pedagogía en Artes Musicales, Pedagogía en Artes Plásticas, Pedagogía en Educación Física y Pedagogía en Filosofía.

El total de la población de estudio fue de 154 personas, esto es, la totalidad del estudiantado de la facultad de educación que realizaba su práctica profesional en educación secundaria durante el primer semestre académico del año 2017. Se les entregó un consentimiento informado acerca del objetivo de la investigación y la importancia de la información que podían aportar. Debido al carácter voluntario de la encuesta, se consiguió una muestra de 102 participantes.

\subsection{Técnicas de recolección}

La recolección de datos se realizó a través de un cuestionario con una escala Likert de carácter voluntario. El instrumento permitió determinar el grado de apreciación positivo, neutral o negativo de los diversos aspectos a estudiar, los cuales están clasificados por dimensiones de estudio. Se incluye también una pregunta abierta que permitió obtener información sobre un punto específico de la investigación. El instrumento de medición fue validado a través de juicio de expertos, quienes determinaron la coherencia y pertinencia de los distintos aspectos a medir y el cuestionario a aplicar.

El instrumento utilizado consta de 25 aspectos a estudiar, los cuales se clasifican en cuatro dimensiones distintas y que son:

- Asesoría y capacitación: En esta dimensión se espera que el profesorado principiante, quienes ejecutarán los programas de orientación, haya recibido la información necesaria y apoyo de parte del equipo técnico de orientación del respectivo centro educativo.

- Conocimiento: En esta dimensión se espera que el profesorado en práctica maneje todo el conocimiento requerido de las diferentes temáticas que deben abordar para la correcta aplicación de los programas de orientación. 
- Estrategias metodológicas: Se espera que el profesorado jefe maneje las estrategias metodológicas necesarias. En otras palabras, que utilicen las herramientas TIC y complementen con variados recursos metodológicos de apoyo.

- Efectividad de los programas de orientación en el aula: Referido a encontrar la existencia de coherencia y pertinencia entre los conocimientos, estrategias metodológicas y las respectivas asesorías y capacitación requeridas para el desarrollo de los programas de orientación.

Se incluyó también una pregunta abierta referente a los aspectos a mejorar o fortalecer en los programas de orientación que se implementan en los centros de práctica.

\subsection{Procesamiento de análisis}

La información obtenida durante el proceso de recolección de datos fue analizada de manera descriptiva. Las preferencias de las personas encuestadas se registraron sobre la base de los cinco niveles de apreciación que contempla la escala tipo Likert (nunca, casi nunca, a veces, casi siempre y siempre). La información se analizó en cada dimensión por frecuencias absolutas y porcentuales, con el software estadístico Statistical Package for the Social Sciences (SPSS) versión 20.0. La pregunta abierta se codificó sobre la base de tres grandes aspectos asociados (fortalecer, agregar y cambiar), posteriormente se tabularon los datos y analizaron.

\section{Resultados}

Para analizar los datos, se organizaron en 4 dimensiones: Asesoría y Capacitación, Conocimiento, Estrategias Metodológicas y Efectividad de los nuevos programas de orientación en la Sala de Clases.

\subsection{Dimensión 1: Asesoría y Capacitación}

Tabla 1

Porcentaje del estudiantado según nivel de apreciación de la aplicación de la dimensión asesoría y capacitación, Universidad de Concepción-Chile, 2017.

\begin{tabular}{|c|c|c|c|c|c|c|}
\hline Ítem & $\begin{array}{c}\text { No } \\
\text { responde }\end{array}$ & Nunca & $\begin{array}{c}\text { Casi } \\
\text { Nunca }\end{array}$ & $\begin{array}{c}A \\
\text { veces }\end{array}$ & $\begin{array}{c}\text { Casi } \\
\text { siempre }\end{array}$ & Siempre \\
\hline $\begin{array}{l}\text { ITEM 1: He recibido información por parte del } \\
\text { equipo directivo o del equipo de Orientación del } \\
\text { centro educativo en relación con los programas de } \\
\text { estudio de Orientación }\end{array}$ & $0,0 \%$ & $30,6 \%$ & $22,5 \%$ & $16,3 \%$ & $17,3 \%$ & $13,3 \%$ \\
\hline $\begin{array}{l}\text { ÍTEM 2: He recibido asesoramiento en la } \\
\text { aplicación del programa de Orientación del centro } \\
\text { educativo en el aula. }\end{array}$ & $0,0 \%$ & $35,7 \%$ & $24,5 \%$ & $21,4 \%$ & $11,2 \%$ & $7,1 \%$ \\
\hline
\end{tabular}


ÍTEM 3: Durante el desarrollo del programa de Orientación he recibido supervisión directa en el aula por parte del profesor jefe guía.

ÍTEM 4: Estimo necesario el acompañamiento de parte del centro educativo para aplicar los Programas de Orientación

ÍTEM 5: Considero que estoy realmente capacitado/capacitada para ejecutar los Programas de la asignatura de Orientación.

ÍTEM 6: Participo en reuniones formales con el profesor jefe guía para realizar retroalimentación de las clases de Orientación ya realizadas.

Fuente: Elaboración propia (2017).

$1,0 \% \quad 14,3 \% \quad 2,0 \% \quad 12,2 \% \quad 22,5 \% \quad 48,0 \%$

$\begin{array}{llllll}4,1 \% & 3,1 \% & 6,1 \% & 17,3 \% & 25,5 \% & 43,9 \%\end{array}$

$1,0 \% \quad 4,1 \% \quad 13,3 \% \quad 26,5 \% \quad 43,9 \% \quad 11,2 \%$

$2,0 \% \quad 27,6 \% \quad 14,3 \% \quad 30,6 \% \quad 10,2 \% \quad 15,3 \%$

Tomando como base la Tabla 1, podemos observar que el 53,1\% de las personas encuestadas nunca o casi nunca recibió información por parte de los establecimientos educacionales referente a los programas de Orientación. También se observa que un 60,2\% asegura nunca o casi nunca haber recibido asesoramiento por parte del centro educativo al aplicar los programas en el aula. La supervisión al profesorado en práctica fue permanente en casi la mitad de los casos (48\%) y tan solo un $14,3 \%$ dijo no haber recibido supervisión alguna.

Un $69,4 \%$ de los participantes considera que el acompañamiento por parte del centro educativo es necesario siempre o casi siempre a la hora de aplicar los Programas y tan solo un $4,1 \%$ nunca se sintió capacitado para ejecutarlos.

En cuanto a la retroalimentación, esta fue más bien inconsistente, pues tan solo un $15,3 \%$ contó con ella de manera permanente. Poco más de un cuarto de quienes participaron en esta encuesta $(27,6 \%)$ no tuvo retroalimentación alguna.

\subsection{Dimensión 2: Conocimiento.}

Tabla 2

Porcentaje del estudiantado según nivel de apreciación de la aplicación de la dimensión conocimiento, Universidad de Concepción-Chile, 2017.

\begin{tabular}{|c|c|c|c|c|c|c|}
\hline Ítem & No responde & Nunca & Casi Nunca & $\begin{array}{c}A \\
\text { veces }\end{array}$ & $\begin{array}{c}\text { Casi } \\
\text { siempre }\end{array}$ & Siempre \\
\hline $\begin{array}{l}\text { ITEM 7: Mis conocimientos me han permitido } \\
\text { aplicar los programas de Orientación en el } \\
\text { trabajo de aula }\end{array}$ & $1,0 \%$ & $4,1 \%$ & $10,2 \%$ & $20,4 \%$ & $45,9 \%$ & $18,4 \%$ \\
\hline $\begin{array}{l}\text { ITEM 8: Los contenidos de los programas de } \\
\text { Orientación del centro educativo presentan } \\
\text { dificultades para ser abordados. }\end{array}$ & $4,1 \%$ & $14,3 \%$ & $28,6 \%$ & $36,7 \%$ & $9,2 \%$ & $7,1 \%$ \\
\hline $\begin{array}{l}\text { ITEM 9: Considero que los contenidos en los } \\
\text { programas de Orientación del centro educativo } \\
\text { son necesarios para orientar de forma efectiva } \\
\text { a los estudiantes. }\end{array}$ & $3,1 \%$ & $7,1 \%$ & $8,2 \%$ & $16,3 \%$ & $35,7 \%$ & $29,6 \%$ \\
\hline $\begin{array}{l}\text { ITEM 10: Considero que Los programas de } \\
\text { Orientación del centro educativo proponen }\end{array}$ & $3,0 \%$ & $8,2 \%$ & $21,4 \%$ & $29,6 \%$ & $28,6 \%$ & $9,2 \%$ \\
\hline
\end{tabular}


todas las herramientas necesarias para trabajar de manera adecuada.

ITEM 11: Considero que los programas de Orientación del centro educativo están dirigidos a la realidad socioeducativa actual.

ITEM 12: Considero que los programas de Orientación del centro educativo proponen contenidos para abordar las problemáticas de los estudiantes.

Fuente: Elaboración propia (2017)

De la Tabla 2 podemos extraer que la mayoría de quienes fueron encuestados consideró que sus conocimientos les han permitido aplicar los Programas de Orientación (45\%,9 casi siempre y 18,4\% siempre; $64,3 \%$ del total). Mencionan también que los contenidos de dichos programas suelen presentar dificultades para ser abordados (tan solo un 14,3\% dijo nunca haber encontrado dificultades) y que los Programas de Orientación son necesarios para orientar de forma efectiva al estudiantado (un 29,6\% dijo que siempre eran necesarios para orientar de forma efectiva, mientras un $35,7 \%$ dijo que casi siempre lo eran; $65,3 \%$ del total. Las personas encuestadas manifiestan que los Programas de Orientación de los centros educativos no proponen todas las herramientas necesarias para trabajar de manera adecuada (tan solo un $9,2 \%$ dijo que siempre encontró todas las herramientas necesarias para trabajar adecuadamente en ellos), y mencionan también que tienen cierta coherencia con la realidad socio-educativa actual, (sólo el 7,1\% consideró que nunca tenían coherencia) y por último que los programas suelen proponer contenidos para abordar problemáticas estudiantiles (solo un 10,2\% dijo que nunca lo hacen, mientras que el a veces tiene un $27,6 \%$ y el casi siempre un $36,7 \%$ de las preferencias).

\subsection{Dimensión 3: Estrategias Metodológicas}

Tabla 3

Porcentaje del estudiantado según nivel de apreciación de la aplicación de la dimensión estrategias metodológicas, Universidad de Concepción-Chile, 2017.

\begin{tabular}{|c|c|c|c|c|c|c|}
\hline Ítem & No responde & Nunca & $\begin{array}{c}\text { Casi } \\
\text { Nunca }\end{array}$ & $\begin{array}{c}\text { A } \\
\text { veces }\end{array}$ & $\begin{array}{c}\text { Casi } \\
\text { siempre }\end{array}$ & Siempre \\
\hline $\begin{array}{l}\text { ITEM 13: En el centro educativo se complementa } \\
\text { con variados recursos metodológicos, tales como } \\
\text { videos o presentación de diapositivas, el desarrollo } \\
\text { de los programas de Orientación. }\end{array}$ & $1,0 \%$ & $16,3 \%$ & $15,3 \%$ & $22,5 \%$ & $20,4 \%$ & $24,5 \%$ \\
\hline $\begin{array}{l}\text { ITEM 14: El centro educativo dispone de los } \\
\text { recursos tecnológicos necesarios para la correcta } \\
\text { aplicación de los programas de Orientación. }\end{array}$ & $1,0 \%$ & $1,0 \%$ & $5,1 \%$ & $16,4 \%$ & $30,6 \%$ & $45,9 \%$ \\
\hline $\begin{array}{l}\text { ITEM 15: Los lineamientos entregados en los } \\
\text { programas de Orientación desarrollados en el } \\
\text { centro educativo limitan o dificultan la ejecución de } \\
\text { estrategias metodológicas. }\end{array}$ & $6,1 \%$ & $14,3 \%$ & $29,6 \%$ & $32,7 \%$ & $13,3 \%$ & $4,0 \%$ \\
\hline ITEM 16: Considero que los programas de & $5,1 \%$ & $3,1 \%$ & $6,1 \%$ & $17,3 \%$ & $34,7 \%$ & $33,7 \%$ \\
\hline
\end{tabular}




\begin{tabular}{|c|c|c|c|c|c|c|}
\hline $\begin{array}{l}\text { Orientación del centro educativo requieren } \\
\text { preparación previa en el aspecto metodológico para } \\
\text { su correcto desarrollo. }\end{array}$ & & & & & & \\
\hline $\begin{array}{l}\text { ITEM 17: Los programas de Orientación del centro } \\
\text { educativo entregan o proponen pautas de trabajo } \\
\text { aplicables a los estudiantes en el aula }\end{array}$ & $4,1 \%$ & $8,2 \%$ & $15,3 \%$ & $30,6 \%$ & $20,4 \%$ & $21,4 \%$ \\
\hline $\begin{array}{l}\text { ITEM 18: Los lineamientos de los programas de } \\
\text { Orientación del centro educativo entregan la } \\
\text { libertad de aplicar diferentes estrategias } \\
\text { metodológicas. }\end{array}$ & $4,1 \%$ & $7,1 \%$ & $14,3 \%$ & $25,5 \%$ & $32,7 \%$ & $16,3 \%$ \\
\hline $\begin{array}{l}\text { ITEM 19: Los profesores jefes del centro educativo } \\
\text { participan de manera colaborativa para } \\
\text { intercambiar estrategias metodológicas en el } \\
\text { desarrollo de los programas de Orientación. }\end{array}$ & $4,1 \%$ & $20,4 \%$ & $19,4 \%$ & $21,4 \%$ & $16,3 \%$ & $18,4 \%$ \\
\hline
\end{tabular}

Fuente: Elaboración propia (2017).

De acuerdo con la información entregada por la tabla 3, podemos observar que, en el 16,3\% de los casos no se observó utilización de recursos metodológicos variados, pero dado que el $67,4 \%$ de la población encuestada eligió las categorías a veces (22,5\%), casi siempre $(20,4 \%)$ o siempre $(24,5 \%)$, podemos decir que regularmente se observó utilización de estos. Además, las personas encuestadas apreciaron que los centros educativos dispongan de los recursos tecnológicos necesarios; siempre 45,9\% de las veces y casi siempre 30,6\% de las veces, por lo que podemos deducir que gran parte de los establecimientos cuentan con los recursos tecnológicos necesarios para aplicar los Programas de Orientación.

También podemos concluir que los lineamientos entregados en los programas de Orientación desarrollados en los centros educativos, ocasionalmente, limitan o dificultan la ejecución de estrategias metodológicas, pues predomina el a veces con $32,7 \%$ seguido del casi nunca con $29,6 \%$ y el nunca con un $14,3 \%$ de las preferencias (el porcentaje de siempre es $4 \%$ y el de casi siempre es $13,3 \%$ para una mejor comparación).

Asimismo, un 68,4\% considera que los programas siempre $(33,7 \%)$ o casi siempre $(34,7 \%)$ requieren preparación previa en el aspecto metodológico para su correcto desarrollo y se aprecia que los programas suelen proponer o entregar pautas de trabajo aplicables al estudiantado en el aula ya que entre las preferencias siempre $(21,4 \%)$, casi siempre $(20,4 \%)$ y a veces $(30,6 \%)$ tenemos el $72,4 \%$ de los datos.

Al analizar el ítem 18, podemos deducir que los lineamientos de los programas de Orientación del centro educativo suelen dar la libertad de aplicar diferentes estrategias metodológicas ya que solo un 7,11\% optó por el nunca y la opción casi siempre se llevó el mayor porcentaje $(32,7 \%)$ de las preferencias.

Para finalizar, el $20,4 \%$ dijo que nunca participó de manera colaborativa con el profesorado jefe del centro educativo para intercambiar estrategias metodológicas en el 
desarrollo de los programas de Orientación, por lo que en la mayoría de los casos hubo al menos un tanto de colaboración.

\subsection{Dimensión 4: Efectividad de los nuevos Programas de Orientación en la Sala de Clases}

Tabla 4

Porcentaje del estudiantado según nivel de apreciación de la aplicación de la dimensión Efectividad de los nuevos Programas de Orientación en la Sala de Clases, Universidad de Concepción-Chile, 2017.

\begin{tabular}{|c|c|c|c|c|c|c|}
\hline Ítems & No responde & Nunca & Casi Nunca & $\begin{array}{c}\mathrm{A} \\
\text { veces }\end{array}$ & $\begin{array}{c}\text { Casi } \\
\text { siempre }\end{array}$ & Siempre \\
\hline $\begin{array}{l}\text { ITEM 20: Los estudiantes se interesan por los } \\
\text { contenidos tratados en los programas de } \\
\text { Orientación del centro educativo. }\end{array}$ & $1,0 \%$ & $12,2 \%$ & $33,7 \%$ & $30,6 \%$ & $19,4 \%$ & $3,1 \%$ \\
\hline $\begin{array}{l}\text { ITEM 21: Se observaron cambios positivos en la } \\
\text { conducta de los estudiantes tras aplicar los } \\
\text { programas de Orientación en el centro educativo. }\end{array}$ & $2,1 \%$ & $10,2 \%$ & $21,4 \%$ & $46,9 \%$ & $16,3 \%$ & $3,1 \%$ \\
\hline $\begin{array}{l}\text { ITEM 22: Existen problemáticas que no están } \\
\text { presentes o no han sido abordados por los } \\
\text { programas de Orientación del establecimiento }\end{array}$ & $4,1 \%$ & $3,1 \%$ & $8,2 \%$ & $42,8 \%$ & $31,6 \%$ & $10,2 \%$ \\
\hline $\begin{array}{l}\text { ITEM 23: Los programas de Orientación de la } \\
\text { institución pueden aplicarse a más de una } \\
\text { realidad social de forma transversal, } \\
\text { independiente del estudiante o el establecimiento } \\
\text { educacional. }\end{array}$ & $4,1 \%$ & $5,1 \%$ & $13,3 \%$ & $34,7 \%$ & $26,5 \%$ & $16,3 \%$ \\
\hline $\begin{array}{l}\text { ITEM 24: Los programas de Orientación del } \\
\text { centro educativo permiten resolver de forma } \\
\text { satisfactoria algún problema o situación de algún } \\
\text { estudiante en particular. }\end{array}$ & $4,1 \%$ & $9,2 \%$ & $18,4 \%$ & $35,7 \%$ & $27,5 \%$ & $5,1 \%$ \\
\hline $\begin{array}{l}\text { ITEM 25: Los estudiantes participan de manera } \\
\text { activa durante el desarrollo de los programas de } \\
\text { Orientación en el centro educativo. }\end{array}$ & $3,1 \%$ & $11,2 \%$ & $16,3 \%$ & $35,7 \%$ & $28,6 \%$ & $5,1 \%$ \\
\hline
\end{tabular}

Fuente: Elaboración propia (2017).

De acuerdo con la Tabla 4, se observa que la apreciación del profesorado en práctica es que el estudiantado receptor de los programas se interesa por los contenidos tratados en los programas de Orientación de forma ocasional, puesto que un 33,7\% respondió casi nunca y un $30,6 \%$ a veces, lo que deja en evidencia que existe una falta de interés del alumnado hacia la asignatura de Orientación. Además, 46,9\% de quienes participaron dice que a veces se observan cambios positivos en el estudiantado luego de aplicar el programa, mientras que un $21,4 \%$ señala que casi nunca y un $10,2 \%$ dice nunca, evidenciando que los programas pocas veces suelen desencadenar cambios en el estudiantado.

Al observar el ítem 22 podemos ver que tan solo un 3,1\% asegura que los programas de Orientación cubren todas las problemáticas del alumnado. En otras palabras, la gran mayoría del profesorado en práctica se encontró con problemas que no trató el programa de orientación. 
En el ítem 23, podemos ver que solo el 5,1\% de las personas encuestadas dijo que los programas de Orientación de las instituciones nunca pueden aplicarse a más de una realidad social de forma transversal, independiente del perfil estudiantil o el establecimiento educacional, con lo que da a entender que la mayoría de los programas sí pueden ser aplicados a estudiantes de distintas realidades sociales con algún nivel de éxito, aunque solo en $16,3 \%$ de los casos, las personas encuestadas consideraron que siempre eran aplicables.

En el ítem 24 solo el 5,1\% consideró que los programas de Orientación de los centros educativos permiten resolver siempre de forma satisfactoria algún problema o situación de algún estudiante en particular, por cual se deduce que estos programas no presentan una muy buena cobertura con respecto a la totalidad de problemas con los que puede contar el alumnado.

Para finalizar, observando que en el ítem 25 hay 16,3\% en casi nunca, 35,7\% en a veces y $28,6 \%$ en casi siempre, podemos deducir que el estudiantado participa ocasionalmente de manera activa durante el desarrollo de los programas de Orientación y tan solo un $5,1 \%$ de las personas encuestadas dijo haber observado una participación permanente.

\subsection{Análisis datos Pregunta abierta}

La pregunta abierta realizada fue ¿Qué aspectos reemplazaría, fortalecería o agregaría al Programa de Orientación del centro educativo en que usted realiza su práctica profesional?

El propósito de esta pregunta fue recopilar información respecto a las falencias o fortalezas que el profesorado en práctica pedagógica pudo observar en la implementación del programa de Orientación en su respectivo centro de práctica.

Sobre la base de las respuestas de las personas encuestadas se generaron 3 categorías que permitieron organizar los datos obtenidos. Estas categorías son:

- Fortalecer: Engloba los puntos dirigidos hacia fortalecer los contenidos y herramientas ya existentes en los Programas de Orientación.

- Cambiar: Se centra en puntos que deberían ser completamente modificados dentro de los Programas de Orientación y su ejecución

- Agregar: reúne ideas que no se encuentran presentes dentro de los Programas de Orientación. 
Tabla 5

Frecuencia y porcentaje de estudiantes según categorías y subcategorías relacionadas a aspectos del Programa de Orientación, Universidad de Concepción-Chile, 2017.

\begin{tabular}{llrr}
\hline \multicolumn{1}{c}{ Categoría } & Subcategoría & Frecuencia & \multicolumn{2}{c}{ Porcentaje } \\
\hline \multirow{3}{*}{ Fortalecer } & Aplicación del programa & 20 & $21,74 \%$ \\
& Contextualizar el programa & 16 & $17,39 \%$ \\
& Apoyo y Asesoramiento & 13 & $14,13 \%$ \\
& Aspectos valóricos & 4 & $4,35 \%$ \\
\hline \multirow{3}{*}{ Cambiar } & No se aprecia uso del programa & 13 & $14,13 \%$ \\
& Actitud del profesor & 2 & $2,17 \%$ \\
& Personal administrativo & 3 & $3,26 \%$ \\
\multirow{2}{*}{ Agregar } & Cambios en los programas & 14 & $15,22 \%$ \\
\hline \multirow{2}{*}{} & Trabajo grupal del personal del & 7 & $7,61 \%$ \\
\hline & establecimiento & 72 & $100,00 \%$ \\
\hline
\end{tabular}

Fuente: Elaboración propia (2017)

Como podemos observar en la tabla 5, la mayoría de las respuestas $(57,61 \%)$ se centraron en la categoría Fortalecer, donde destacan las subcategorías de aplicación del programa de Orientación (21,74\%) y la contextualización del este (17,39\%). La primera categoría engloba los puntos dirigidos hacia fortalecer los contenidos y herramientas ya existentes en los Programas de Orientación. La segunda categoría destacada por la población encuestada fue Cambiar, con un $34,78 \%$ de los datos, donde "realizar cambios a los programas" $(15,22 \%)$ y "No se aprecia uso del programa" (14,13\%) fueron las subcategorías destacadas. La categoría Agregar contiene tan solo una subcategoría relacionada al trabajo en equipo del personal del establecimiento, con solo un $7,61 \%$ de las preferencias.

\section{Conclusiones}

Sobre la base de los datos obtenidos, podemos concluir que los centros educativos no participan sistemáticamente del proceso formador en el área de la orientación educativa de estudiantado en práctica. Sólo en algunos casos la población de practicantes fue acompañada y supervisada por una persona agente especializada o mentora, quien asume el rol de testigo y crítico. En otros casos, simplemente se supervisa al estudiantado en su práctica pedagógica profesional, sin entregar ningún tipo de retroalimentación.

Respecto al manejo de conocimientos, el estudiantado en práctica pedagógica profesional considera sentirse preparado para aplicar los programas de orientación en el 
aula. El estudiantado en práctica considera que los contenidos de los programas no presentan dificultades para ser abordados. Destaca la importancia de tales contenidos al momento de ejercer la orientación, ya que están contextualizados a las realidades socioeducativas de los centros, sin embargo, muchos abordan solo parcialmente las problemáticas de la población estudiantil de cada establecimiento.

Es importante mencionar que los programas de Orientación son propuestos para trabajar distintos temas de interés en el aula. El profesorado encargado de ejecutarlos, 0 bien, el agente encargado del proceso de Orientación en el centro educativo tiene la facultad de modificar o ajustar los contenidos a la realidad particular del estudiantado del establecimiento.

Con respecto a los recursos metodológicos que acompañan el desarrollo de los programas de Orientación, el estudiantado en práctica pedagógica profesional percibió que los centros educativos cuentan con los recursos tecnológicos necesarios. Además, los lineamientos de los programas no limitan ni dificultan la ejecución de estrategias metodológicas. El cuerpo docente, en algunos casos, participa de manera colaborativa para intercambiar estrategias metodológicas en el desarrollo de los programas de orientación. Sin embargo, hay falencias en cuanto a la asesoría y capacitación que debiera tener el profesorado para trabajar los programas. Además, se aprecian disimilitudes en cuanto al trabajo colaborativo. En algunos centros es considerado como parte del proceso de práctica, mientras que en otros no hay colaboración entre el cuerpo docente. Si consideramos que los agentes del proceso educativo deben trabajar como un equipo, esto se convierte en un tema controversial.

El estudiantado en práctica profesional no percibe que los programas aborden todas las problemáticas a las que se enfrentan en el establecimiento. No obstante, destacan que los programas son aplicables transversalmente a las distintas realidades de los establecimientos chilenos.

Los resultados arrojan que las dimensiones en las cuales las personas encuestadas manifestaron mejor percepción fueron las de conocimiento y estrategias metodológicas. Mientras que presentan una percepción negativa en las dimensiones de asesoría, capacitación y efectividad de los programas de orientación en el aula. Ante la evidencia de esta dificultad, las instituciones educativas deberían motivar y asesorar al profesorado para que puedan capacitarse y así promover un efectivo desarrollo de los programas de orientación en el aula. Asimismo, se hace necesario realizar estudios de seguimiento acerca 
de la efectividad del desarrollo de los programas de orientación desde la mirada de los educandos en los diferentes niveles de enseñanza.

Finalmente, la universidad debe reforzar el rol del tutor o tutora en la formación inicial docente. Quienes acompañan en el proceso formativo deben enfatizar y fortalecer las competencias profesionales quienes serán docentes en el futuro.

\section{Agradecimientos}

Damos las gracias a todas las personas e instituciones que apoyaron de manera directa o indirecta el desarrollo de esta investigación: a la Universidad de Concepción (UDEC), al estudiantado en práctica pedagógica profesional de la Facultad de Educación, a los establecimientos educacionales de la provincia de Concepción- Chile, al profesorado de la Universidad de Concepción y de los centros educativos que participaron en el estudio. También a todos aquellos compañeros, amigos y familiares que, de alguna manera, colaboraron y apoyaron el desarrollo del proyecto.

\section{Referencias}

De Abreu, Joane; De Abreu, Joseane y Albornoz, Omar. (2014). La importancia del profesor tutor. Revista interfaces, 1(1). Recuperado de http://interfacesnead.uespi.br/revistas/index.php/ed1/article/view/11/pdf 4.

Díaz, Víctor. (2006). Formación docente, practica pedagógica saber pedagógico. Laurus, 12(Extr.), 88-103. Recuperado de https://www.redalyc.org/pdf/761/76109906.pdf

García-Loor, Ana. y Chanca, Antonio. (2016). La consejería estudiantil y la convivencia educativa. Revista científica Dominio de las Ciencias, 2(3), 108-118. Recuperado de https://dominiodelasciencias.com/ojs/index.php/es/article/view/123

García, María. (2016). El desarrollo de la Orientación educativa en el aprendizaje-servicio (Tesis doctoral). Departamento de Didáctica y Teoría de la Educación Facultad de Formación de Profesorado y Educación Universidad Autónoma de Madrid, España. Junio 2016. Recuperado de

https://repositorio.uam.es/bitstream/handle/10486/674897/garcia lopez maria lourdes. $\underline{\text { pdf }}$

González, Julio y Ledezma, María. (2009). La Orientación en América Latina: consideraciones generales acerca de los criterios de coherencia, cooperación y calidad. Orientación y sociedad. 9. Recuperado de http://www.scielo.org.ar/pdf/orisoc/v9/v9a02.pdf

González, Julio. (2008). La Orientación profesional en América Latina: Fortalezas, debilidades, amenazas y oportunidades. Revista Mexicana de Orientación Educativa, 
5(13), 44-49. Recuperado de http://pepsic.bvsalud.org/pdf/remo/v5n13/v5n13a09.pdf

González-Pienda, Julio. (2007). Los retos de la familia hoy ante la educación de sus hijos: a educar también se aprende. Revista gallego-portuguesa de psicología y educación, 15 (2), 187-201. Recuperado de http://ruc.udc.es/dspace/bitstream/handle/2183/7080/RGP 1513 Cong.pdf?sequence= 1

Hernández Sampieri, Roberto; Fernández Collado, Carlos; y Baptista Lucio, María del Pilar (2014). Metodología de la investigación: Roberto Hernández Sampieri, Carlos Fernández Collado y Pilar Baptista Lucio (6a. ed.). México D.F.: McGraw-Hill. Recuperado de https://periodicooficial.jalisco.gob.mx/sites/periodicooficial.jalisco.gob.mx/files/metodolo gia de la investigacion - roberto hernandez sampieri.pdf

Jiménez, Esther. (2008). El papel del profesorado en la actualidad. Su función docente y social. Foro de educación, 10(1). Recuperado de https://dialnet.unirioja.es/servlet/articulo?codigo $=2907073$

Ley № 18962. Diario Oficial de la República de Chile, Santiago, Chile, 10 de marzo de 1990. Recuperado de https://www.leychile.cl/Navegar?idNorma=30330

Martínez Garrido, Cynthia; Krichesky, Gabriela \& García Barrera, Alba. (2010). El orientador escolar como agente interno de cambio. Revista Iberoamericana de Educación, 54(1), 107-122. Recuperado de https://doi.org/10.35362/rie540544

Ministerio de Educación, Chile. (1982). Decreto № 300 Exento: Aprueba planes y programas para la educacion media humanistico-cientifica (última modificación: 04-junio-1998 Decreto 220). Santiago de Chile: Ministerio de Educación. Biblioteca del Congreso Nacional de Chile. Recuperado de https://www.leychile.cl/Navegar?idNorma=12108\&idParte=\&idVersion=1998-06-04

Ministerio de Educación, Chile. (1980). Decreto № 4.002: Fija objetivos, planes y programas de la educacion general basica, a partir de 1981. Santiago de Chile: Ministerio de Educación. Biblioteca del Congreso Nacional de Chile. Recuperado de https://www.leychile.cl/Navegar?idNorma=19411\&idParte=0\&idVersion=

Ministerio de Educación, Chile. (2015). Bases curriculares $7^{\circ}$ básico a $2^{\circ}$ medio. Santiago, Chile: Ministerio de Educación. Biblioteca Digital Mineduc, p.340-369. Recuperado de https://bibliotecadigital.mineduc.cl/handle/20.500.12365/654?show=full

Ministerio de Educación, Chile. (2017). Orientación: Apoyo técnico a los establecimientos educacionales en la apropiación e implementación de la Asignatura de Orientación séptimo año de enseñanza básico a segundo año de enseñanza media. Santiago, Chile: Ministerio de Educación. Biblioteca Digital Mineduc. Recuperado de https://bibliotecadigital.mineduc.cl/handle/20.500.12365/493 
Molina Contreras, Denyz Luz. (2004). Concepto de orientación educativa: diversidad y aproximación: Diversidad y aproximación. Revista Electrónica Iberoamericana de Educación, 35(1), 1-22. Recuperado de https://rieoei.org/historico/deloslectores/736Molina108.PDF

R. Moreno, Elsa Amanda. (2017). Concepciones de práctica pedagógica. Folios, (16), 105.129. Recuperado de https://doi.org/10.17227/01234870.16 folios 105.129

Parras Laguna, Antonia; Madrigal Martínez, Ana María; Redondo Duarte, Sara; Vale Vasconcelos, Patricia; Enrique Navarro Asencio. (2008). Orientación educativa: fundamentos teóricos, modelos institucionales y nuevas perspectivas. Recuperado de https://orientacascales.files.wordpress.com/2013/10/centro-de-investigacion-ydocumentacion-educativa gobierno-de-espa a orientacion-educativa -fundamentosteoricos modelos-institucionales-y-nuevas-perspe.pdf

Pérez, Julio y Osses, Sonia. (2015). Investigación educativa medioambiental en estudiantes secundarios urbanos. Estudios pedagógicos online, 41(1), 219-235. Recuperado de https://scielo.conicyt.cl/scielo.php?script=sci arttext\&pid=S0718-07052015000100013

Sanz, Rafael. (2010). El profesor como tutor: un reto a consolidar en el ejercicio profesional de la Orientación. Revista española de Orientación y psicopedagogía, 21(2). Recuperado de http://revistas.uned.es/index.php/reop/article/view/11537

Tarrida, Antoni. (2012). Perfil competencial del tutor o de la tutora de Enseñanza Secundaria. Revista Española de Orientación y Psicopedagogía, 23(2). Recuperado de https://www.redalyc.org/pdf/3382/338230791003.pdf 


\section{ANEXO 1: INSTRUMENTO DE MEDICIÓN}

\subsection{Encuesta tipo Likert aplicada}

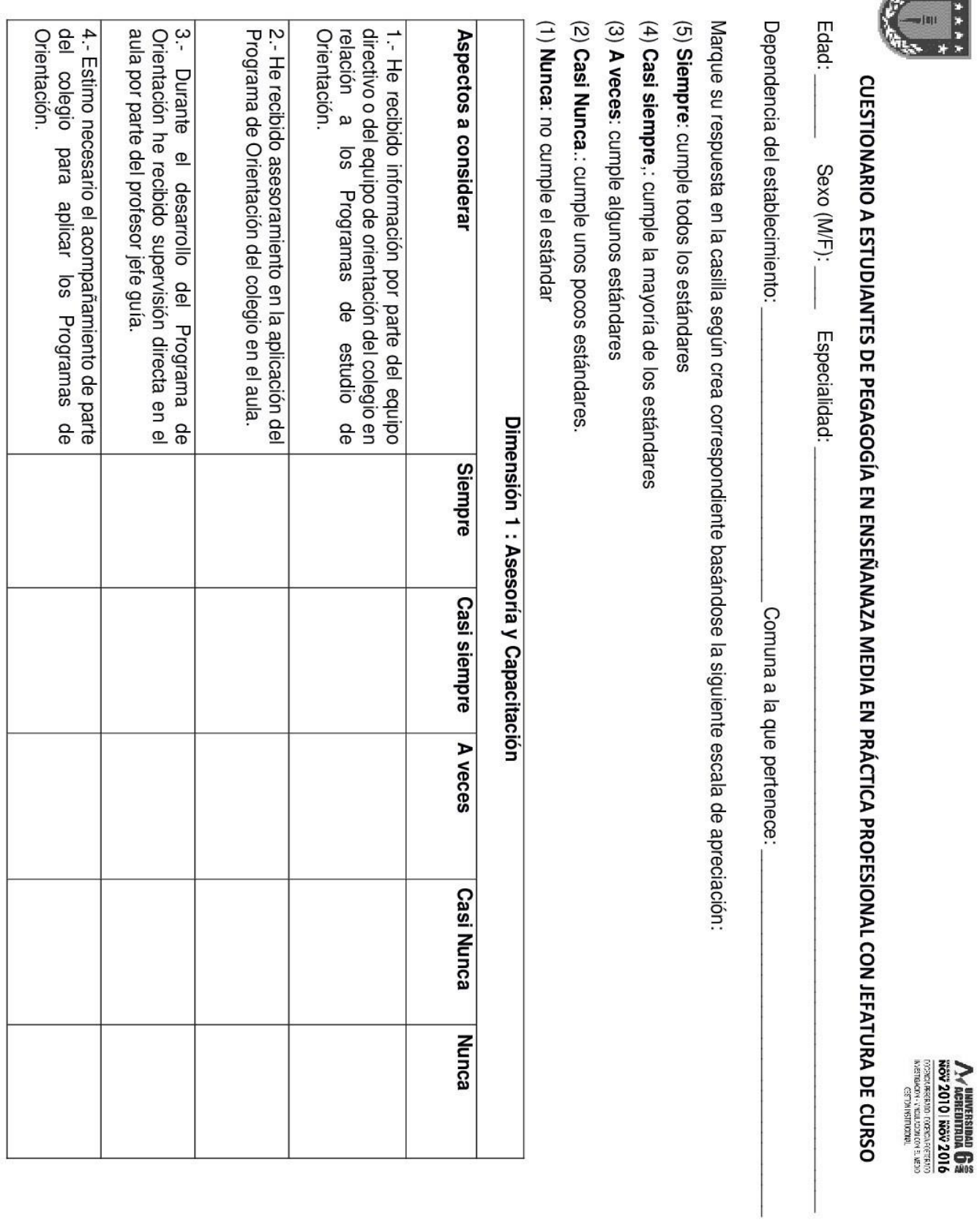




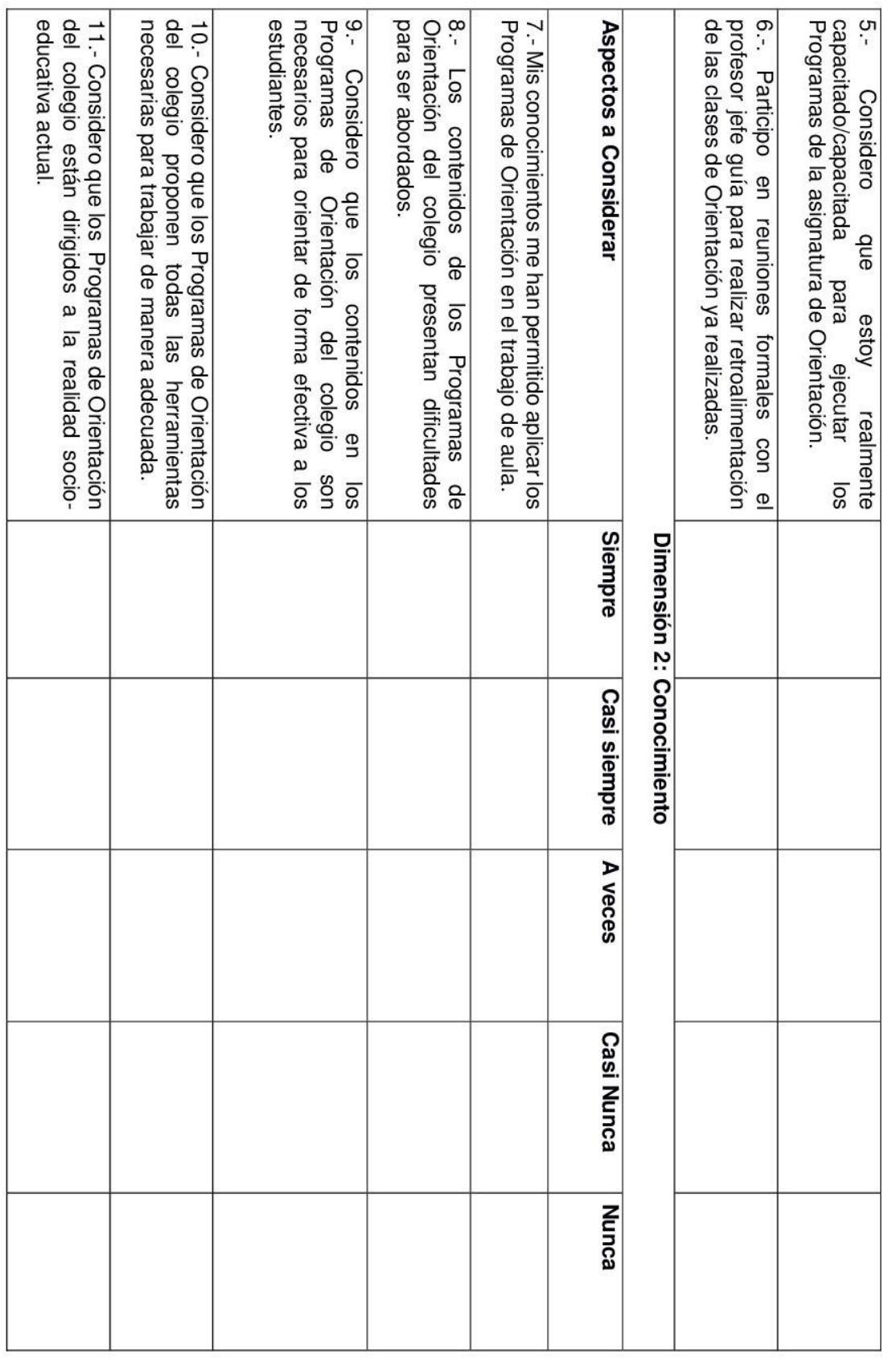
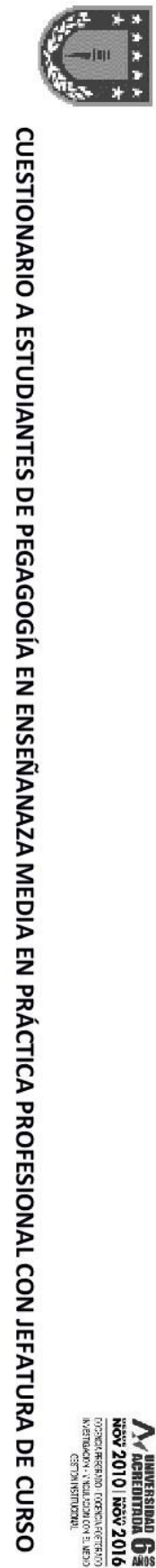

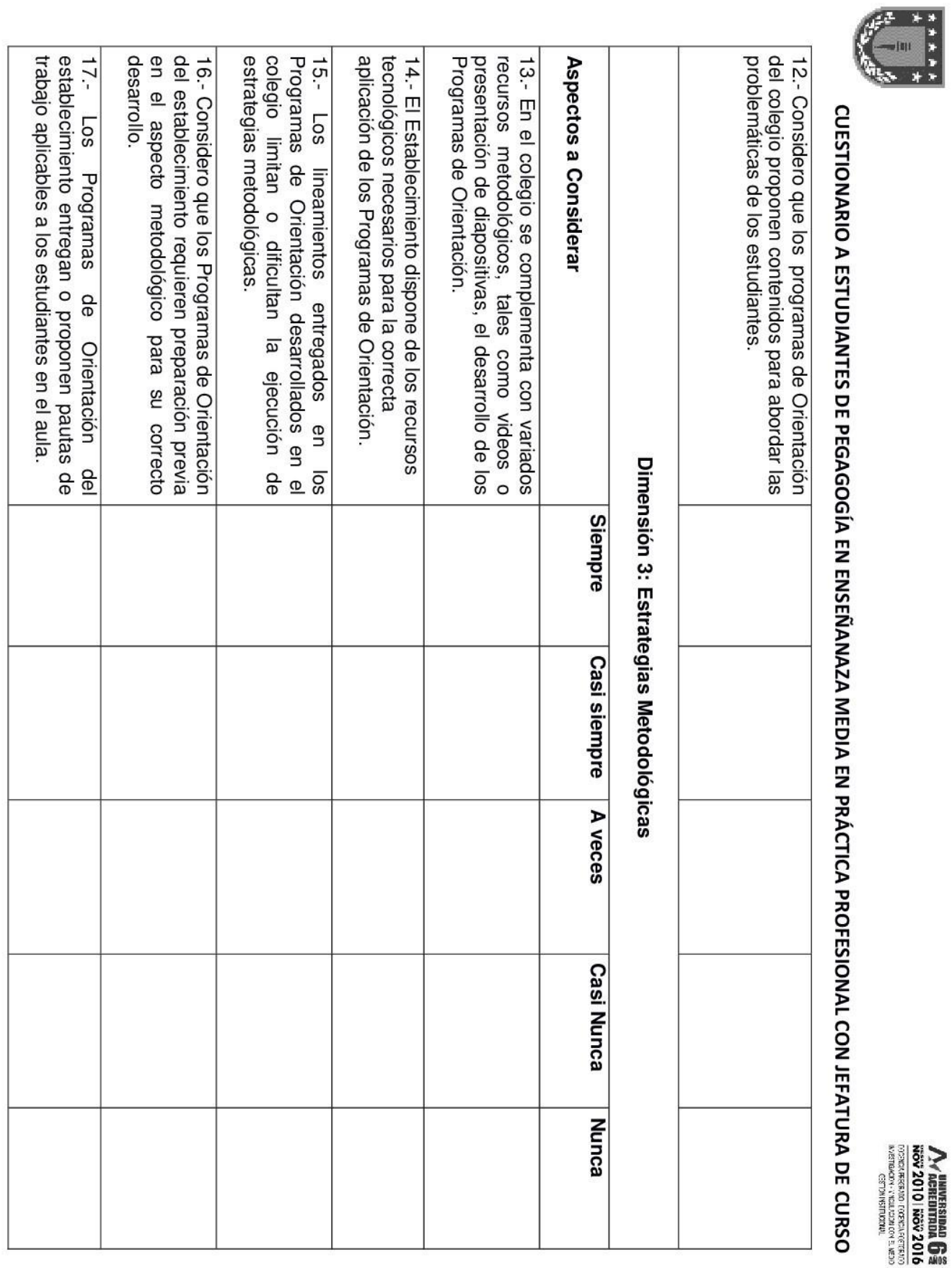


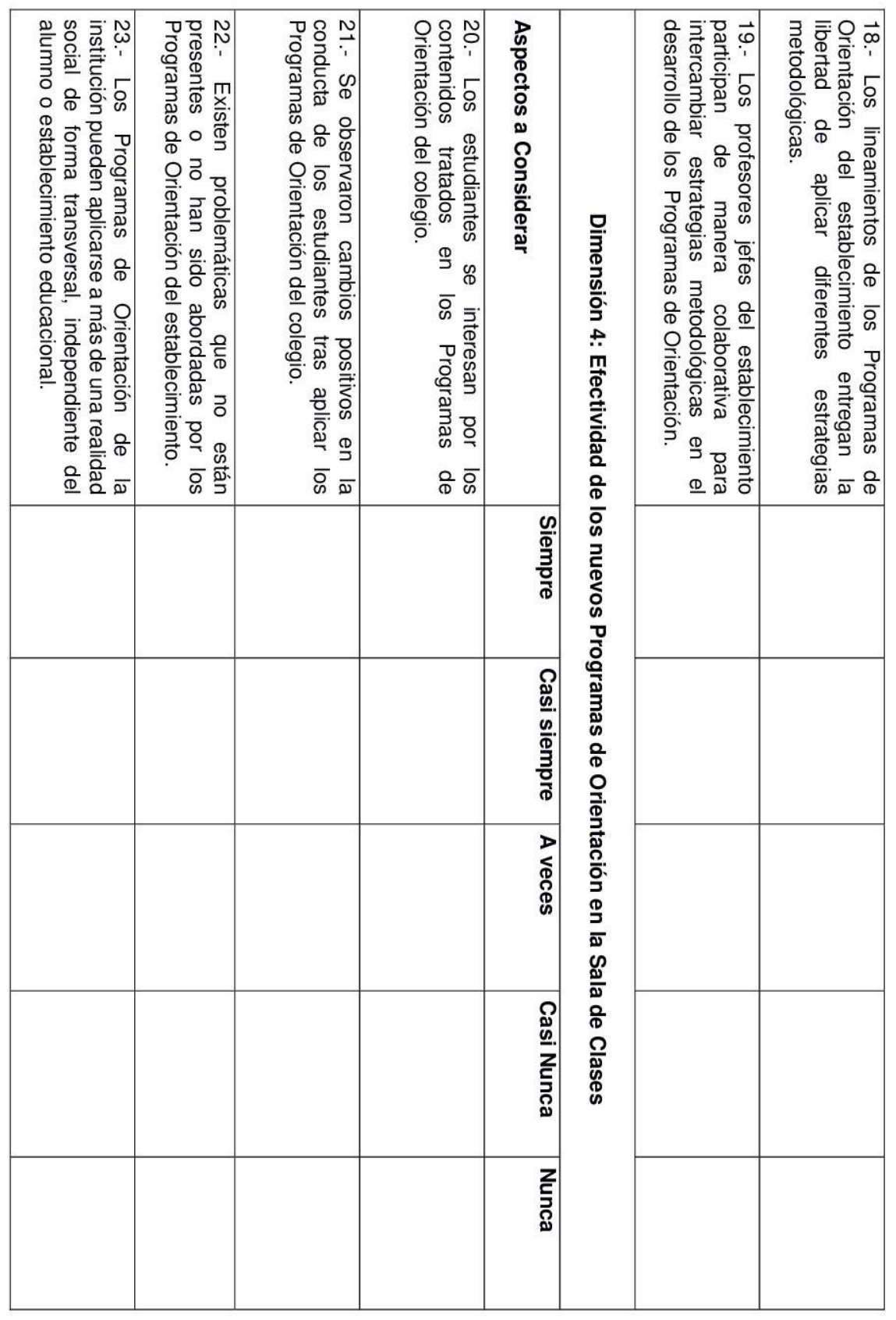

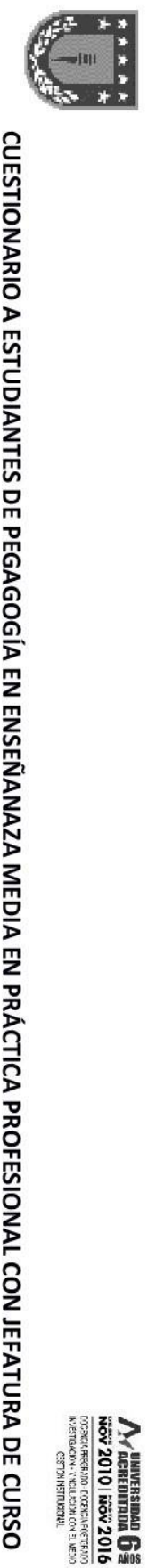




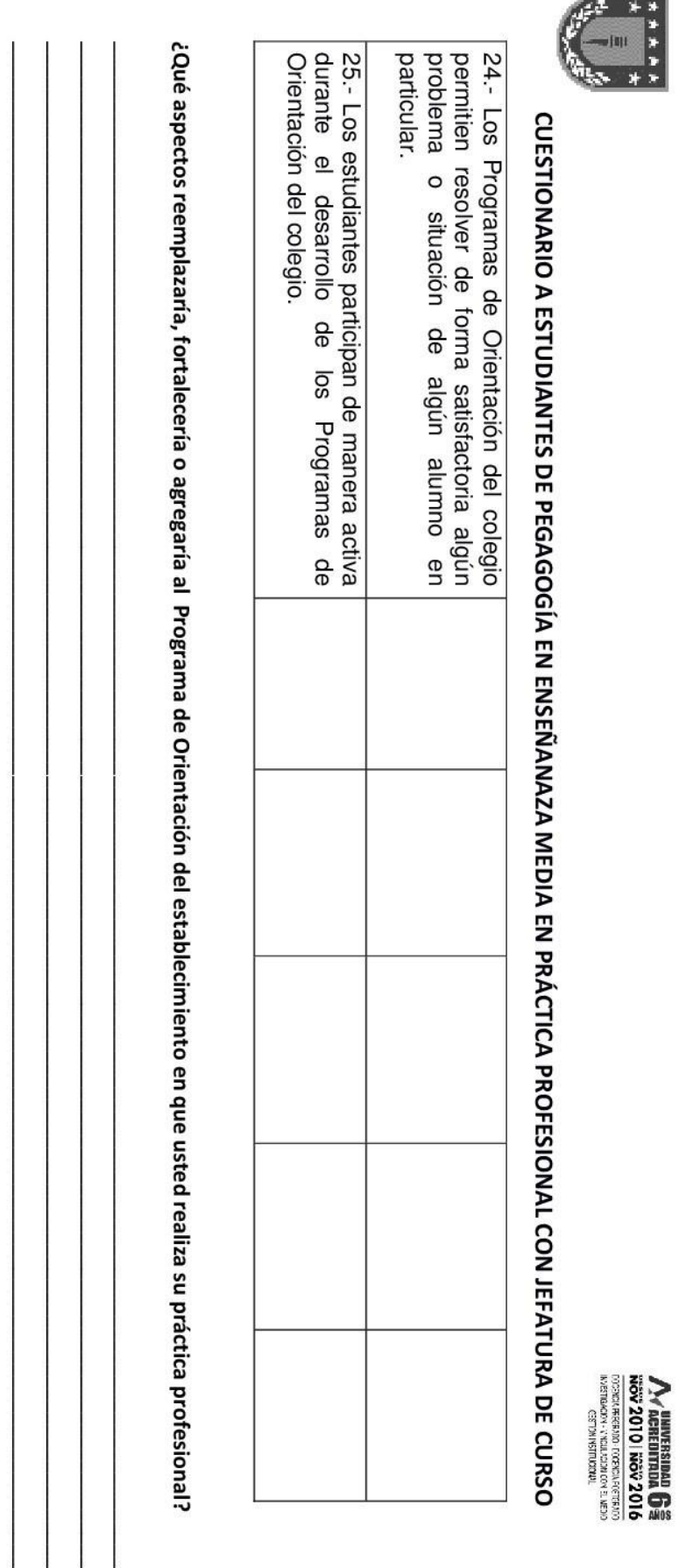


Revista indizada en

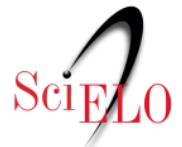

redalyc satindex

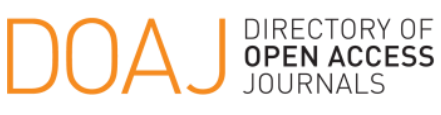

Distribuida en las bases de datos:

๑ Dialnet

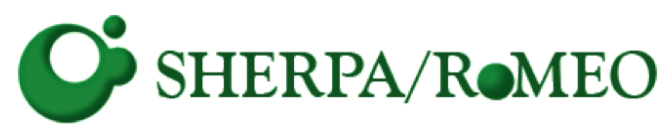

REDIB

Red Iberoamericana

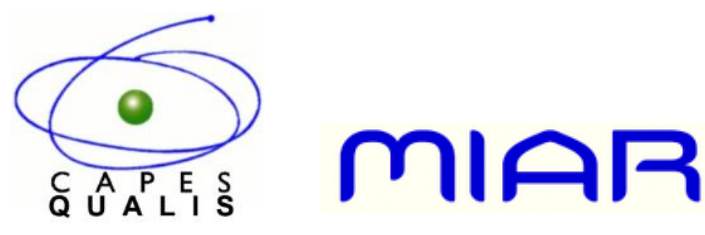

